\title{
Optimal Choices for the E-Tailer with Inventory Rationing, Hybrid Channel Strategies, and Service Level Constraint under Multiperiod Environments
}

\author{
Yuepeng Cheng, ${ }^{1,2}$ Bo Li, ${ }^{1}$ and Yushan Jiang ${ }^{1}$ \\ ${ }^{1}$ College of Management and Economics, Tianjin University, Tianjin 300072, China \\ ${ }^{2}$ College of Computer and Remote Sensing Information Technology, North China Institute of Aerospace Engineering, \\ Langfang 065000, China
}

Correspondence should be addressed to Yushan Jiang; yshjiang@tju.edu.cn

Received 23 October 2015; Accepted 16 December 2015

Academic Editor: Paulina Golinska

Copyright (C) 2016 Yuepeng Cheng et al. This is an open access article distributed under the Creative Commons Attribution License, which permits unrestricted use, distribution, and reproduction in any medium, provided the original work is properly cited.

\begin{abstract}
This paper investigates optimal choices for the e-tailer with inventory rationing, hybrid channel strategies, and service level constraint under multiperiod environment. Based on different operational conditions, five mathematical models are proposed for the e-tailer who faces two types of fuzzy demand and a framework is designed to illustrate the e-tailer's operation in different models. This paper presents the advantages of inventory rationing and hybrid channel strategies and analyzes the influences of channel differences variability on optimal choices for the e-tailer, where the channel differences include margin difference of priority and margin difference of channel. Through computer simulation, the optimal choices for the e-tailer under different multiperiod environments are obtained, and the influences of margin difference of priority and margin difference of channel on the e-tailer's optimal choices are also examined. Experiment results show that the pure-play drop shipping model and the hybrid channel with inventory rationing model are the optimal choices for the e-tailer; these findings have valuable guiding significance for the e-tailer to make optimal tactical decisions under multiperiod environment.
\end{abstract}

\section{Introduction}

China's E-Commerce Report (2014) shows that the total amount of Chinese e-commerce transactions is up to $¥ 13.4$ trillion in 2014, achieving an increase of $28.8 \%$, which is 3.86 times the growth rate of GDP (i.e., 7.4\%). E-commerce has become a new impetus to promote economic growth in China [1]. For example, as Tmail, one company of Alibaba Group, achieved 9 Guinness world records during the Single's Day sales on November 11, 2015. Beside generating "highest online sales revenue generated by a single company in 24 hours” with ¥91,217,036,022, Tmail sold 10,124,263 liters of milk, $6,567,661 \mathrm{~kg}$ of nuts, $641,899 \mathrm{~kg}$ of apples, $269,821 \mathrm{~kg}$ of honey, 3,133,289 sets of mobile phones, 643,964 sets of TV, $1,112,561$ watches, and 6,506 cars in 24 hours [2]. People were surprised by these achievements, and they wonder how these goods reach the customers in time.
The rapid development of e-commerce requests more on the e-fulfillment, which is the critical operation of distributing the goods to the customers, so the e-tailer tries to improve service level of e-fulfillment, and adopts drop shipping as an e-fulfillment option. With the popular of drop shipping in e-commerce, the e-tailer can choose two different basic operational models, which include the pure-play drop shipping e-tailer model and the traditional e-tailer model [3]. The pure-play e-tailer has no inventory and saves the cost of running an inventory system, but gets the risk from the supplier failing in drop shipping. If the supplier makes mistake in drop shipping, customers will complain the pureplay e-tailer and the pure-play e-tailer bears the penalty cost, but not the supplier, so the pure-play e-tailer wants to own an in-house inventory to depress this adverse impact. The traditional e-tailer depends on in-house inventory to satisfy 
demand and then bears the cost of operating an inventory system; thus, the traditional e-tailer wants to utilize the supplier's drop shipping to cut this cost. The pure-play etailer runs an in-house inventory besides drop shipping, and the traditional e-tailer adopts drop shipping besides in-house inventory; then, the new hybrid channel e-tailer model is generated, which is application of hybrid channel strategy. The e-tailer with hybrid channel strategy can alternatively choose in-house inventory and drop shipping to serve the customers, and the e-tailer wants to know whether the hybrid channel e-tailer model is better than the pure-play drop shipping e-tailer model and the traditional e-tailer model.

In addition, if different demand types bring the same profit to the e-tailer, then the e-tailer will treat all types of demand equally. When the e-tailer gets different margins from different demand types, the e-tailer has the power to fulfill the demand type with higher margin first compared to the others. Furthermore, when the e-tailer obtains different margins from different demand types with different efulfillment options, the e-tailer should use the e-fulfillment option with more profit to satisfy the demand type with higher margin first. In this situation, the e-tailer with limited drop shipping ability faces a problem: how to allocate stock for different demand types to get more profit. There are many cases of adoption on inventory rationing strategy with multiple types of demand [4-6]; the similar situations also exist in the airline, car rent, hotel service, and other businesses (e.g., Bitran and Mondschein [7], Geraghty and Johnson [8], and Subramanian et al. [9]). When the e-tailer uses inventory rationing strategy in the in-house inventory, two new models are obtained; they are the traditional e-tailer with inventory rationing model and the hybrid channel e-tailer with inventory rationing model. In another aspect, this paper extends the assumption about drop shipping service of the supplier [10] and the drop shipping ability of the supplier is limited; the supplier cannot fulfill all the requests from the e-tailer, so the service level of the supplier's drop shipping is constrained.

The motivation of this research comes from the e-tailer who sells products on the internet under multiperiod environment. The e-tailer gets different margins from the same units of demand by different e-fulfillment options, whereas they obtain different margins from different types of demand with the same e-fulfillment option. In order to get more profit under multiperiod environment with inventory rationing, hybrid channel strategies, and service level constraint, the etailer wants to know which model is optimal under certain multiperiod environment, and how channel differences are influent on the optimal choices in e-commerce. Through computer simulation, this paper analyzes these problems and gets the optimal choices for the e-tailer within different mathematical models. The advantages of inventory rationing and hybrid channel strategies are also evaluated in this study.

The contributions of this research are as follows. (1) Besides the evaluations of inventory rationing and hybrid channel strategies, this study analyzes the optimal choices of the e-tailer with service level constraint to maximize profit under different multiperiod environments. (2) Through computer simulation, this paper examines the influences of channel differences variability on the optimal choices for the e-tailer under multiperiod environment with fuzzy demand and fuzzy lead time, which include margin difference of priority and margin difference of channel. (3) Though there is service level constraint in lots of inventory systems (e.g., Li et al. [11]), the drop shipping ability of the supplier is limited, and the supplier provides different service levels for different demand types, unfulfilled demand in traditional inventory system seems as backorder [12-14] or lost sale [1517], but in this study some of this demand will be fulfilled by drop shipping and the remaining seems to be lost sale which results in penalty cost for the e-tailer. These results have much useful information for the e-tailer to make the optimal choices under multiperiod environment with fuzzy demand and fuzzy lead time.

The remainder of this paper is organized as follows. Section 2 presents a review of related literature about inventory rationing and hybrid channel strategies. In Section 3, five mathematical models are outlined for the e-tailer, which include the pure-play drop shipping e-tailer model, the traditional e-tailer model, the traditional e-tailer with inventory rationing model, the hybrid channel e-tailer model, and the hybrid channel e-tailer with inventory rationing model. Numerical analysis illustrates the results about the positive effect of inventory rationing and hybrid channel strategies for the e-tailer in Section 4. Section 5 shows the channel differences influent on the optimal choices for the e-tailer. Finally, Section 6 provides the conclusion and discusses the future possible extensions.

\section{Literature Review}

2.1. Inventory Rationing Strategy. It is valuable to classify demand according to certain difference and treat different types of demand with different e-fulfillment options for the e-tailer. As a basis for classification, there are some different measurements which include shortage cost, lead time, service level and others.

The types of demand were characterized firstly by different shortage cost. Veinott [18] was one of the first researchers studying inventory rationing strategy with $n$ demand classes, zero lead time, and backorder under multiperiod environment; the demand in different periods was independent but not necessarily identically distributed. Evans [15] designed a single product inventory system with two types of demand. Nahmias and Demmy [19] firstly evaluated a continuous review $(R, Q)$ inventory system with rationing policy; they focused on service levels of two Poisson demand classes with given threshold and reorder level. Demand differed by backorder cost. Ha [16] designed the same model with several demand classes and lost sale, compared the optimal rationing policy with the first-come first-serve policy in a queuing model through numerical study, and investigated the value of stock rationing strategy. Moon and Kang [13] considered a support level control policy in four models with various demand types. These demand types had different priorities based on their holding and shortage cost. If the inventory system had insufficient stock, low priority demand was backordered. Melchiors et al. [20] studied $(s, Q)$ inventory model with two demand classes. They used a critical 
level policy and low priority demand would be rejected whenever the inventory position was less than the critical level. The Poisson demand was characterized by penalty cost. Möllering and Thonemann [21] adopted a critical level policy in inventory system with arbitrary lead time and two demand classes, which were different in penalty cost. They used multidimensional Markov chain to model a periodic review inventory system.

There were also some other researches where the types of demand differed by lead time, service level, and so forth; Cattani and Souza [22] studied a production system with inventory rationing strategy in direct market. Two Poisson demand classes were different in lead time. Customers chose different delivery ways and paid different prices. They analyzed the inventory rationing strategy under various scenarios. Ayanso et al. [10] evaluated an inventory rationing strategy in a $(R, Q)$ inventory system. The two demand classes were characterized by lead time. They studied the influences of stochastic demand and stochastic lead time on the e-tailer in B2C mode. Chew et al. [23] considered a dynamic rationing policy for two inventory systems with multiple Poisson demand classes under multiperiod environment. Two inventory systems were different in whether lead time was zero. They found that the dynamic rationing policy is better than the static rationing policy under more operating conditions. Hung et al. [14] studied the dynamic threshold rationing problem for an inventory system with several demand classes which differed by service level or price; they considered both single period and multiperiod inventory system with backorder. Wang et al. [6] proposed a multidimensional Markov chain approach in a periodic review inventory system with two demand classes, which required different service level. They analyzed an anticipated rationing policy to satisfy two types of demand. The demand class with high service level should be satisfied first than that with low service level. The demand class with low service level would be backordered when the on hand stock was insufficient. Isotupa and Samanta [17] studied an inventory model with two customer types and stochastic lead time. They provided different service levels for different customer types. When inventory position was less than a threshold level, the remaining stock was reserved for high priority demand, and the low priority demand would be treated as lost sale.

2.2. Hybrid Channel Strategy. Drop shipping had been used by mail-order firms in the 1980s and became one of the primary ways for the e-tailer to fulfill demand on the internet; there was a survey that indicated that $30 \%$ of pure play etailer relied heavily on drop shipping in the e-fulfillment [24]. So far, some researches had been done on hybrid channel strategy of the e-tailer with in-house inventory and drop shipping in the e-commerce. For example, Khouja [25] studied an optimal mixture of drop shipping and in-house inventory under single period environment. With different distributions of demand, the optimal order quantity was got for the e-tailer. Cheng et al. [26] studied the influences of different uncertainties on an e-tailer who used private inventory and drop shipping to fulfill two types of demand, and they designed a framework to get the optimal threshold for the e-tailer's private inventory. They considered the mixture of inventory system and drop shipping for the etailer. Netessine et al. [27] discussed the advantages of drop shipping as an order fulfillment option and analyzed the situations where the e-tailers should adopt drop shipping. Chen et al. [28] designed a mathematical model to analyze the inventory strategies of the e-tailer with private inventory or the third party logistics (i.e., drop shipping); the results showed the situations how the e-tailer to choose the better e-fulfillment option. Bailey and Rabinovich [29] developed an analytical model to study inventory management problem of the e-tailer with drop shipping and inventory channels. They found that the e-tailers should consider both channels if their market shares went up and relied more on in-stock inventory when products became more popular. Netessine and Rudi [3] considered three different inventory models for the e-tailer, which included drop shipping, private inventory, and the combination of them. They used no cooperative game model to study the interaction between the e-tailer and the wholesaler. The results could help the e-tailer to make the optimal inventory decision under different situations. Khouja and Stylianou [30] modeled two $(Q, R)$ inventory systems of the e-tailer on the internet. The e-tailer used drop shipping service to fulfill demand when shortage happened during lead-time. The unmet demand was backordered in the first system whereas lost sale was backordered in the second system.

Lots of previous researches focus on the operational aspects of the e-tailer or the retailer, such as pricing, stocking decision, and inventory rationing. This study evaluates the inventory rationing and hybrid channel strategies from other different perspectives. The goal of this research is principally to explore the optimal choices of the e-tailer with inventory rationing, hybrid channel strategies, and service level constraint under multiperiod environment, and this paper makes several contributions to understand the characteristics of inventory rationing and hybrid channel strategies. One unit of the operational period of five mathematical models is illustrated for the e-tailer and the reason why more and more e-tailers adopting inventory rationing and hybrid channel strategies are found in the comparisons between the models with inventory rationing and hybrid channel strategies and other models without them. Furthermore, the mixture influences of channel differences on the e-tailer' optimal choices are also considered in the experiment. These results will help the e-tailer to make the optimal decisions under multiperiod environment.

\section{Operational Process of the E-Tailer in Different Mathematical Models}

Comparing with other e-tailer models on the internet, this paper focuses on the situations about the e-tailer who uses both in-house inventory and drop shipping to fulfill two different classes of fuzzy demand and the e-tailer wants to choose the optimal mathematical model to get more profit under multiperiod environment. On the one hand, the etailer earns more margins with in-house inventory than drop 
shipping from satisfying the same unit of demand; then the e-tailer should prepare enough stock in order to maximize profit. On the other hand, there are two classes of demand: the priority demand and the common demand. The e-tailer gets more profit from selling the same unit of commodity to the priority demand than the common demand. With limited stock in inventory system, the priority demand should be fulfilled first compared the common demand. In other words, the priority demand has priority compared to the common demand in the e-fulfillment.

According to inventory rationing and hybrid channel strategies, the e-tailer uses in-house inventory to fulfill two classes of demand when stock in the inventory is sufficient. If on-hand stock of in-house inventory reaches or becomes less than the threshold level, the e-tailer fulfills the priority demand by in-house inventory and adopts drop shipping to satisfy all the common demand. Finally, if inventory system has no stock, drop shipping will be used to fulfill both the priority demand and the common demand. These are the efulfillment rules of the e-tailer with inventory rationing and hybrid channel strategies in the e-fulfillment.

The inventory system of the e-tailer used in this paper is a $(R, Q)$ model, which consists of many units of time $t$ and inventory position $P_{t}^{j}$; on hand stock $X_{t}^{j}$ and units on order $O_{t}^{j}$ are used to define the inventory system of e-tailer model $j$, $j \in\{$ II, III, IV , V $\}$. In this section, five mathematical models are designed to analyze the differences of operational process for the e-tailer at time $t$. Equation (1) shows the computation of $P_{t}^{j}$ at time $t ; O_{t}^{j}$ and $X_{t}^{j}$ are changed at time $t$ in (2) and (3), separately. At the end of time $t$, the e-tailer checks $P_{t}^{j}$ and places an order of $Q$ lot size to replenish inventory system if $P_{t}^{j}<R$ :

$$
\begin{aligned}
& P_{t}^{j}=X_{t}^{j}-\sum_{i=1}^{2} D_{t, i}^{\mathrm{inv}, j}, \\
& O_{t}^{j}= \begin{cases}Q, & \mathrm{fa}_{t}^{j}=0, \\
0, & \mathrm{fa}_{t}^{j}=1,\end{cases} \\
& X_{t}^{j}= \begin{cases}\frac{Q}{2}, & t=1, \\
P_{t-1}^{j}+O_{t}^{j}, & t>1,\end{cases}
\end{aligned}
$$

where $j \in\{\mathrm{II}, \mathrm{III}, \mathrm{IV}, \mathrm{V}\}$.

3.1. Model I of the Pure-Play Drop Shipping E-Tailer. The operational process of the pure-play drop shipping e-tailer is as follows; first, two types of demand surf the internet and place orders to the e-tailer; second, the e-tailer gets the demand information from two types of demand and forwards it to the supplier; third, the supplier distributes the products to two types of demand based on the demand information obtained from the e-tailer. With service level constraint of the supplier's drop shipping, a few of demand will not be satisfied and seems as lost sale, which will cause additional penalty cost to the e-tailer. Equation (4) gives two types of

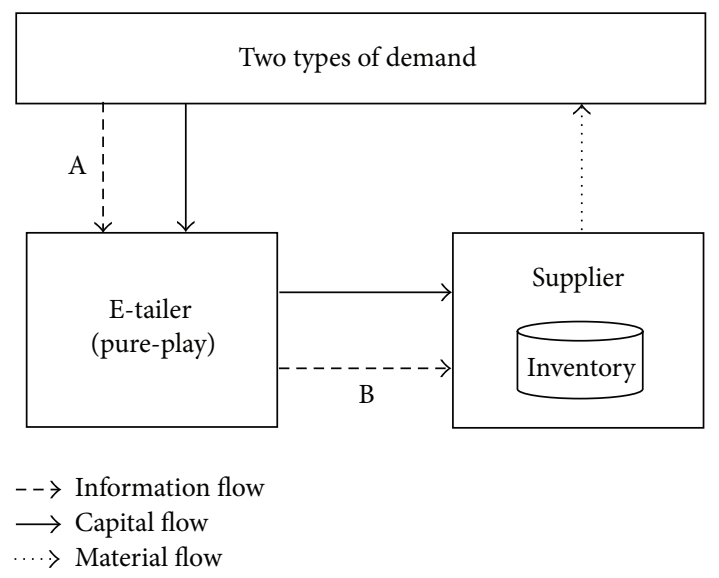

Figure 1: Supply chain of the pure-play drop shipping e-tailer.

demand fulfilled by drop shipping. The lost sale of two classes of demand is shown in (5):

$$
\begin{aligned}
& D_{t, i}^{\mathrm{ds}, \mathrm{I}}=l_{i} D_{t, i}, \quad i \in\{1,2\}, \\
& D_{t, i}^{\mathrm{ls}, \mathrm{I}}=\left(1-l_{i}\right) D_{t, i}, \quad i \in\{1,2\} .
\end{aligned}
$$

Then, the e-tailer's profit function is got in (6). And the supply chain model of the pure-play drop shipping e-tailer is illustrated in Figure 1, where information flows A and B contain the same demand information:

$$
\pi_{t}^{\mathrm{I}}=\sum_{i=1}^{2} v_{i} D_{t, i}^{\mathrm{ds}, \mathrm{I}}-\sum_{i=1}^{2} \mathrm{pc}_{i} D_{t, i}^{\mathrm{ls}, \mathrm{I}}
$$

3.2. Model II of the Traditional E-Tailer. The traditional etailer runs an in-house inventory and replenishes products from the supplier. The e-tailer fulfills the priority demand first because of getting more margins from it than that from the common demand. If on-hand stock cannot fulfill all the priority demand, the remaining and all the common demand will be lost sale. The common demand will be satisfied when on hand stock is not empty after fulfilling the priority demand. If on hand stock is fewer than the quantity of the priority demand, some of the priority demand will be lost sale and cause penalty cost to the e-tailer. The traditional etailer model is shown in Figure 2, where A is the demand information flow and $\mathrm{C}$ is the ordering information flow.

Two types of demand satisfied by inventory system are shown in (7) and (8). The lost sales of two types of demand are computed according to (9). The traditional e-tailer' profit function is as (10), and the e-tailer bears the inventory holding cost and ordering cost in this model:

$$
\begin{aligned}
& D_{t, 1}^{\mathrm{inv}, \mathrm{II}}=\left[D_{t, 1} \wedge X_{t}^{\mathrm{II}}\right]^{+}, \\
& D_{t, 2}^{\mathrm{inv}, \mathrm{II}}=\left[D_{t, 2} \wedge\left(X_{t}^{\mathrm{II}}-D_{t, 1}^{\mathrm{inv}, \mathrm{II}}\right)^{+}\right],
\end{aligned}
$$




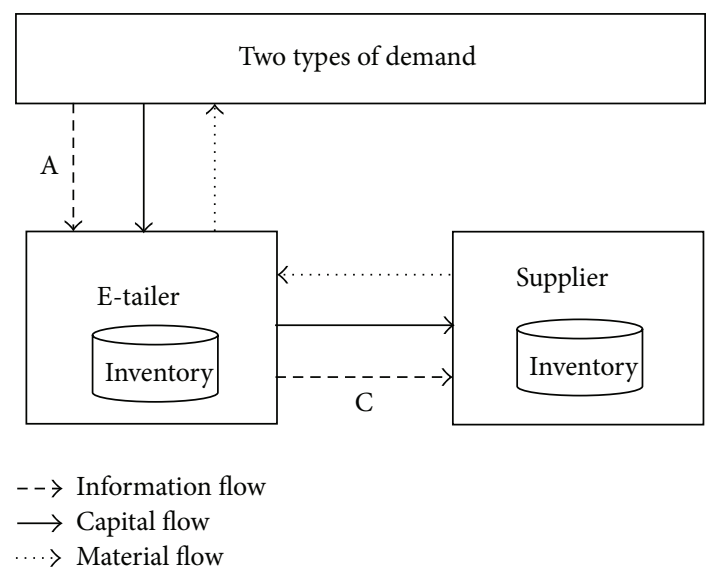

FIGURE 2: Supply chain of the traditional e-tailer.

$$
\begin{aligned}
D_{t, i}^{\mathrm{ls}, \mathrm{II}}= & D_{t, i}-D_{t, i}^{\mathrm{inv}, \mathrm{II}}, \quad i \in\{1,2\}, \\
\pi_{t}^{\mathrm{II}}= & \sum_{i=1}^{2} w_{i} D_{t, i}^{\mathrm{inv}, \mathrm{II}}-h X_{t}^{\mathrm{II}}-k \mathrm{fp}_{t}^{\mathrm{II}} \\
& -\sum_{i=1}^{2} \mathrm{pc}_{i}\left(D_{t, i}-D_{t, i}^{\mathrm{inv}, \mathrm{II}}\right) .
\end{aligned}
$$

3.3. Model III of the Traditional E-Tailer with Inventory Rationing. The difference between model III and model II is the adoption of inventory rationing strategy, which can be found in the comparison between Figures 3 and 2. In this model, the e-tailer runs an in-house inventory and uses the threshold policy to serve two types of demand. Because the priority demand should be satisfied first compared to the common demand, the common demand will be rejected when the on-hand stock is below the threshold. If on-hand stock of the inventory system is not enough to fulfill all the priority demand, the remaining will be lost sale. If the stock left in inventory system is above the threshold after the etailer satisfying the priority demand, the common demand will be fulfilled by in-house inventory. When the in-house inventory is stock out, then all the demand will be lost sale.

Equation (11) shows the common demand satisfied by inhouse inventory. The computation of the priority demand fulfilled by in-house inventory and the lost sales of two classes of demand are the same as model II; then (9) can be extended to (12). The structure of the e-tailer's profit function is similar to (10), and then (13) is used to present the common profit function of the e-tailer in model II and model III:

$$
\begin{aligned}
& D_{t, 2}^{\text {inv,III }} \\
& \quad= \begin{cases}{\left[D_{t, 2} \wedge\left(X_{t}^{\mathrm{III}}-D_{t, 1}^{\mathrm{inv}, \mathrm{III}}\right)^{+}\right],} & X_{t}^{\mathrm{III}}>c, \\
0, & 0 \leq X_{t}^{\mathrm{III}} \leq c,\end{cases} \\
& D_{t, i}^{\mathrm{ls}, j}=D_{t, i}-D_{t, i}^{\mathrm{inv}, j}, \quad i \in\{1,2\}, \quad j \in\{\mathrm{II}, \mathrm{III}\},
\end{aligned}
$$

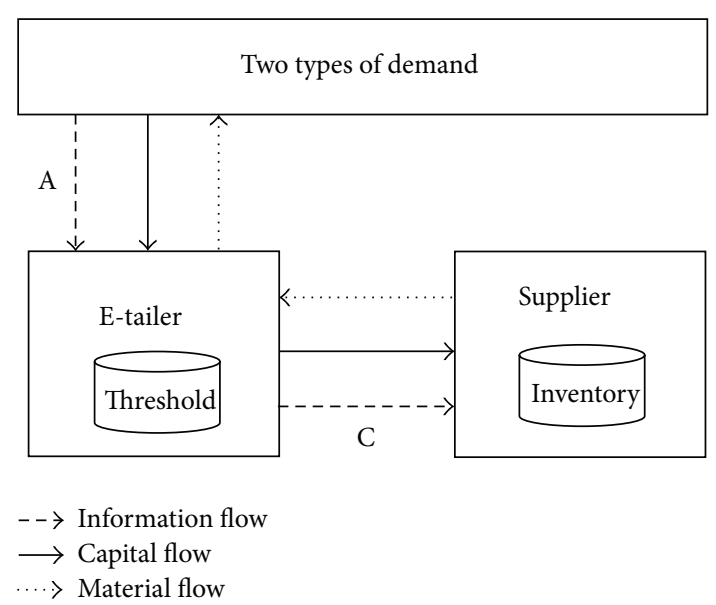

FIGURE 3: Supply chain of the traditional e-tailer with inventory rationing.

$$
\begin{array}{r}
\pi_{t}^{j}=\sum_{i=1}^{2} w_{i} D_{t, i}^{\mathrm{inv}, j}-h X_{t}^{j}-k \mathrm{fp}_{t}^{j}-\sum_{i=1}^{2} \mathrm{pc}_{i}\left(D_{t, i}-D_{t, i}^{\mathrm{inv}, j}\right), \\
j \in\{\mathrm{II}, \mathrm{III}\} .
\end{array}
$$

3.4. Model IV of the Hybrid Channel E-Tailer. Because the pure-play drop shipping e-tailer completely relies on the supplier to fulfill customers, the failure in the drop shipping service causes bad impact directly on the e-tailer, but not the supplier, so the e-tailer runs an inventory system to improve the e-fulfillment performance. In other words, the traditional e-tailer owns an in-house inventory and completely depends on it to satisfy customers; what should the e-tailer do when stock out happens? One solution is drop shipping. The e-tailer who uses both in-house inventory and drop shipping in the efulfillment is denoted as the hybrid channel e-tailer. Figure 4 is supply chain model of the hybrid channel e-tailer, where information flow A includes only demand information, but information flow $\mathrm{D}$ contains ordering information and demand information, which were sent by the e-tailer to the supplier for replenishment and drop shipping, separately.

Two types of demand satisfied by inventory system in model IV are similar to model II, and (8) is extended to (14). The difference between this model and model II is treatment of the demand which can not be satisfied by the e-tailer's inventory system. Some of this demand will be fulfilled by the supplier's drop shipping service, and the remaining will be lost sale, which is calculated by (15) and (16). And the profit function of the hybrid channel e-tailer is shown in (17), which considers the e-tailer's inventory holding cost and ordering cost:

$$
\begin{aligned}
& D_{t, 2}^{\mathrm{inv}, j}=\left[D_{t, 2} \wedge\left(X_{t}^{j}-D_{t, 1}^{\mathrm{inv}, j}\right)^{+}\right], \quad j \in\{\mathrm{II}, \mathrm{IV}\}, \\
& D_{t, i}^{\mathrm{ds}, \mathrm{IV}}=l_{i}\left(D_{t, i}-D_{t, i}^{\mathrm{inv}, \mathrm{IV}}\right), \quad i \in\{1,2\}, \\
& D_{t, i}^{\mathrm{ls}, \mathrm{IV}}=\left(1-l_{i}\right)\left(D_{t, i}-D_{t, i}^{\mathrm{inv}, \mathrm{IV}}\right), \quad i \in\{1,2\},
\end{aligned}
$$




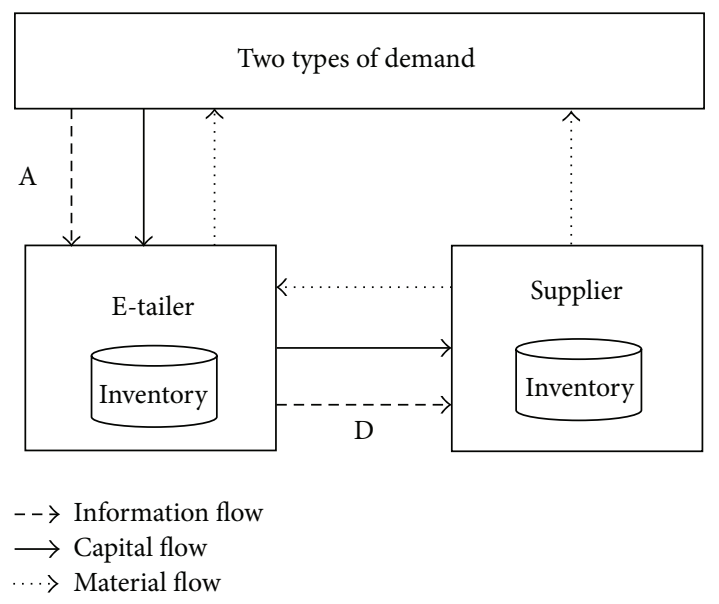

FIGURE 4: Supply chain of the hybrid channel e-tailer.

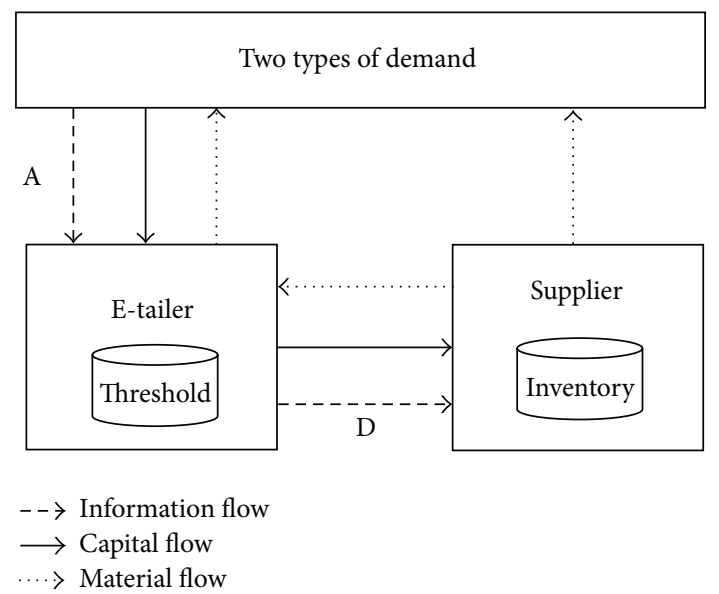

FIGURE 5: Supply chain of the hybrid channel e-tailer with inventory rationing.

$$
\begin{aligned}
\pi_{t}^{\mathrm{IV}}= & \sum_{i=1}^{2} w_{i} D_{t, i}^{\mathrm{inv}, \mathrm{IV}}+\sum_{i=1}^{2} v_{i} D_{t, i}^{\mathrm{ds}, \mathrm{IV}}-h X_{t}^{\mathrm{IV}}-k \mathrm{fp}_{t}^{\mathrm{IV}} \\
& -\sum_{i=1}^{2} \mathrm{pc}_{i}\left(1-l_{i}\right)\left(D_{t, i}-D_{t, i}^{\mathrm{inv}, \mathrm{IV}}\right) .
\end{aligned}
$$

3.5. Model $V$ of the Hybrid Channel E-Tailer with Inventory Rationing. In this model, the e-tailer adopts the threshold policy in inventory system based on model IV, and the etailer's inventory operational process is similar to model III. The difference between this model and model IV is the computation of the common demand which is satisfied by the e-tailer's in-house inventory. And the difference between this model and model III is the arrangement of the demand which cannot be fulfilled by in-house inventory. The supply chain of model $\mathrm{V}$ shows is as shown in Figure 5.

The priority demand fulfilled by the e-tailer's inventory system is obtained same as (7) and the common demand fulfilled by the e-tailer's inventory system is similar to (11); then (7) and (11) can be presented in the new formations of
(18) and (19) separately. Based on (15) and (16), (20) and (21) are used to show the demand satisfied by the supplier's drop shipping service and the lost sale of two types of demand in model IV and model V. And the profit function's structure of the hybrid channel e-tailer in model IV and model V can be expressed in (22):

$$
\begin{aligned}
& D_{t, 1}^{\text {inv }, j}=\left[D_{t, 1} \wedge X_{t}^{j}\right]^{+}, \quad j \in\{\mathrm{II}, \mathrm{III}, \mathrm{IV}, \mathrm{V}\}, \\
& D_{t, 2}^{\text {inv }, j}= \begin{cases}{\left[D_{t, 2} \wedge\left(X_{t}^{j}-D_{t, 1}^{\text {inv }, j}\right)\right],} & X_{t}^{j}>c, \\
0, & 0 \leq X_{t}^{j} \leq c,\end{cases} \\
& j \in\{\text { III, V }\} \text {, } \\
& D_{t, i}^{\mathrm{ds}, j}=l_{i}\left(D_{t, i}-D_{t, i}^{\mathrm{inv}, j}\right), \quad i \in\{1,2\}, j \in\{\mathrm{IV}, \mathrm{V}\}, \\
& D_{t, i}^{\mathrm{ls}, j}=\left(1-l_{i}\right)\left(D_{t, i}-D_{t, i}^{\mathrm{inv}, j}\right), \\
& i \in\{1,2\}, j \in\{\mathrm{IV}, \mathrm{V}\} . \\
& \pi_{t}^{j}=\sum_{i=1}^{2} w_{i} D_{t, i}^{\mathrm{inv}, j}+\sum_{i=1}^{2} v_{i} D_{t, i}^{\mathrm{ds}, j}-h X_{t}^{j}-k \mathrm{f} \mathrm{p}_{t}^{j} \\
& -\sum_{i=1}^{2} \mathrm{pc}_{i}\left(1-l_{i}\right)\left(D_{t, i}-D_{t, i}^{\mathrm{inv}, j}\right) \\
& j \in\{\mathrm{IV}, \mathrm{V}\} .
\end{aligned}
$$

According to five mathematical models, a framework is designed to illustrate their operational processes in every unit of time $t$, which can be seen in Figure 6. The operational variables in every model are obtained by the order of $O_{t}^{j}$, $X_{t}^{j}, D_{t, 1}^{\mathrm{inv}, j}, D_{t, 2}^{\mathrm{inv}, j}, D_{t, 1}^{\mathrm{ds}, j}, D_{t, 2}^{\mathrm{ds}, j}, D_{t, 1}^{\mathrm{ls}, j}, D_{t, 2}^{\mathrm{ls}, j}, \pi_{t}^{j}$, and $P_{t}^{j}, j \in$ $\{$ I, II, III, IV, $\mathrm{V}\} . \mathrm{fa}_{t}^{j}$ represents whether the order arrives at the beginning of time $t$ and is used in the calculation of $O_{t}^{j} \cdot \mathrm{fp}_{t}^{j}$ represents whether the e-tailer needs to place an order and be given the value based on $P_{t}^{j}<R$ when $P_{t}^{j}$ is updated.

\section{Analysis of the Inventory Rationing and Hybrid Channel Strategies with Service Level Constraint}

In this section, the inventory rationing and hybrid channel strategies with service level constraint is evaluated based on five mathematical models in Section 3.1. Comparing the hybrid channel e-tailer with the pure-play e-tailer and the traditional e-tailer, first the advantage of hybrid channel strategy is evaluated. The value of inventory rationing strategy is obtained by analyzing the comparison of model II and model III, as the comparison of model IV and model V. Experiment results show that inventory rationing and hybrid channel strategies are helpful for the e-tailer.

The experiment platform consists of a Dell D630 (RAM: 3 G, CPU: Intel Core 2 Duo T7250 2.0 GHz, HDD: $120 \mathrm{G}$ ) and Matlab (v. R2008a). $t$ is regarded as units of discrete time; 1200 units of discrete time and 300 units of lead time 


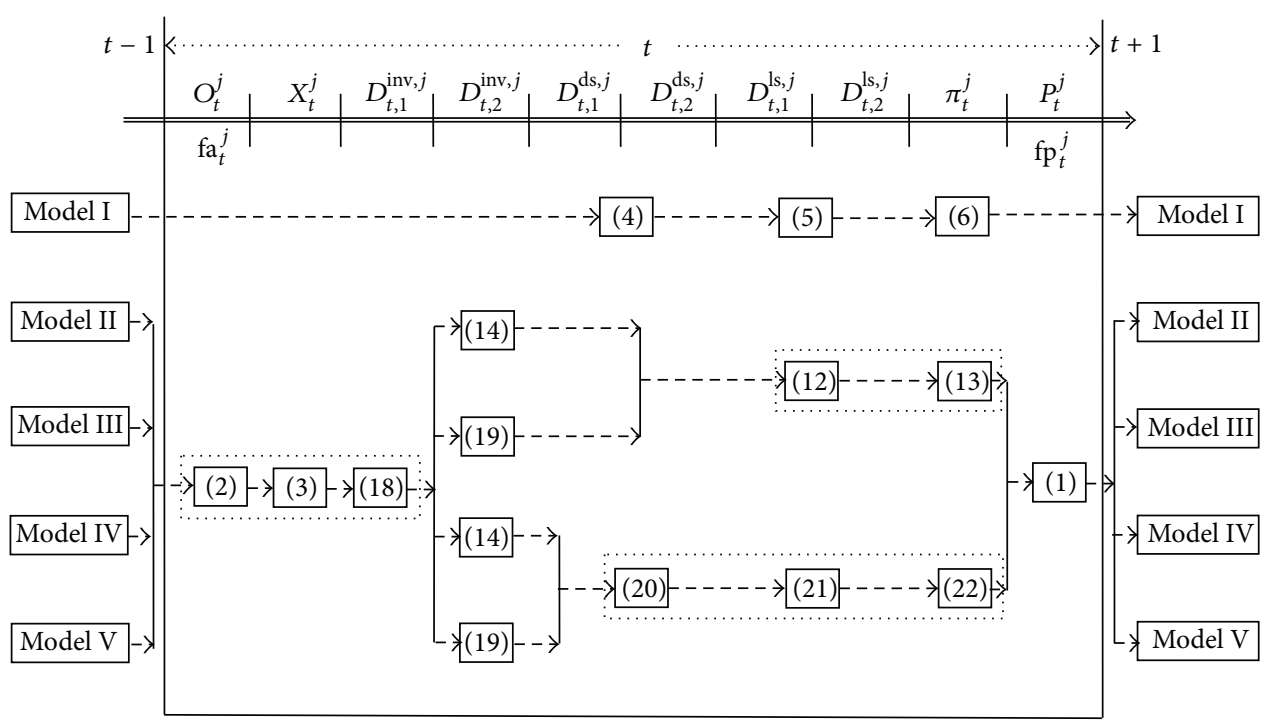

Figure 6: The operational processes of five different e-tailer models in time $t$.

TABLE 1: The values of parameters.

\begin{tabular}{lccccc}
\hline Notations & Values & Notations & Values & Notations & Values \\
\hline$D_{t}$ & $\langle 700,1000,1300\rangle$ & $v_{1}$ & $\$ 5$ & $h$ & $\$ 0.2$ \\
$L$ & $\langle 6,10,14\rangle$ & $v_{2}$ & $\$ 3$ & $k$ & $\$ 1000$ \\
$w_{1}$ & $\$ 16$ & $\mathrm{pc}_{1}$ & $\$ 1.05$ & $\theta$ & $0.1-0.9$ \\
$w_{2}$ & $\$ 7$ & $\mathrm{pc}_{2}$ & $\$ 0.50$ & $X_{1}^{j}$ & 5000 \\
$l_{1}$ & $80 \%$ & $\mathrm{fp}_{t}^{j}$ & $\{0,1\}$ & $O_{1}^{j}$ & 0 \\
$l_{2}$ & $60 \%$ & $\mathrm{fa}_{t}^{j}$ & $\{0,1\}$ & $t$ & 1200 \\
\hline
\end{tabular}

are considered in the experiment, the above $20 \%$ of the simulation data seems as the training data. All the data is generated dynamically in the simulation based on the fuzzy distribution functions. Every inventory operation runs 100 times under certain constraint environment and the means of the results are used for analyzing. The parameters' values used in the experiment are shown in Table 1.

4.1. Evaluation of Inventory Rationing Strategy. When priority preference is rising, the average profits of both model II and model III are increasing. Because the e-tailer can get more margins from the priority demand, more profit will be earned by the e-tailer when priority preference increases. With the priority preference raises from 0.1 to 0.9 , the average profit of model II increases from $\$ 4118$ to $\$ 10590$, and that of model III increases from $\$ 4131$ to $\$ 10859$; Figure 7 shows these variabilities. And the average profit of model III is always higher than model II. The average profit difference between model III and model II is just the value embodiment of inventory rationing strategy. Because the e-tailer can get more margins from fulfilling the same unit of priority demand than common demand with either in-house inventory or drop shipping; the adoption of inventory rationing strategy brings more profit to the e-tailer. Furthermore, Figure 7 shows that the average profit difference between model III and model II

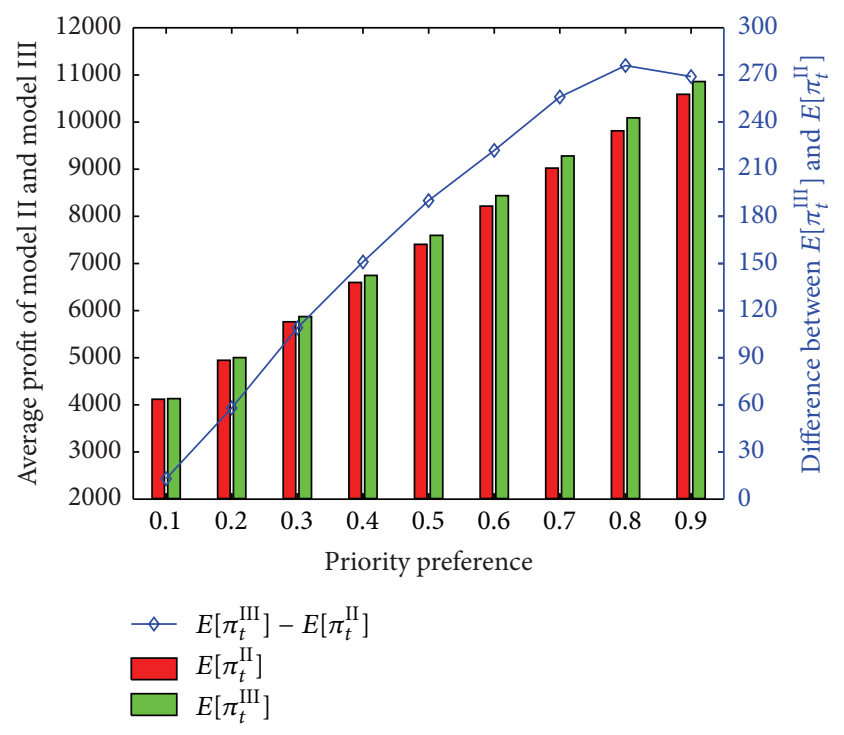

Figure 7: Average profits of model II and model III.

rises gradually with the increasing of the priority preference in most cases. When priority preference becomes very high, the average profit difference between model III and model II will become less than that with moderate high level of priority preference, because the e-tailer should keep more stock in inventory system and places more orders with higher level of priority preference, the increasing of inventory holding cost and ordering cost will depress the e-tailer's profit. The average profit difference between model $\mathrm{V}$ and model IV also has a similar trend to that between model III and model II, and it also presents the positive effect of inventory rationing strategy for the e-tailer.

4.2. Evaluation of Hybrid Channel Strategy. Figure 8 shows that the average profit of model II and model IV has 


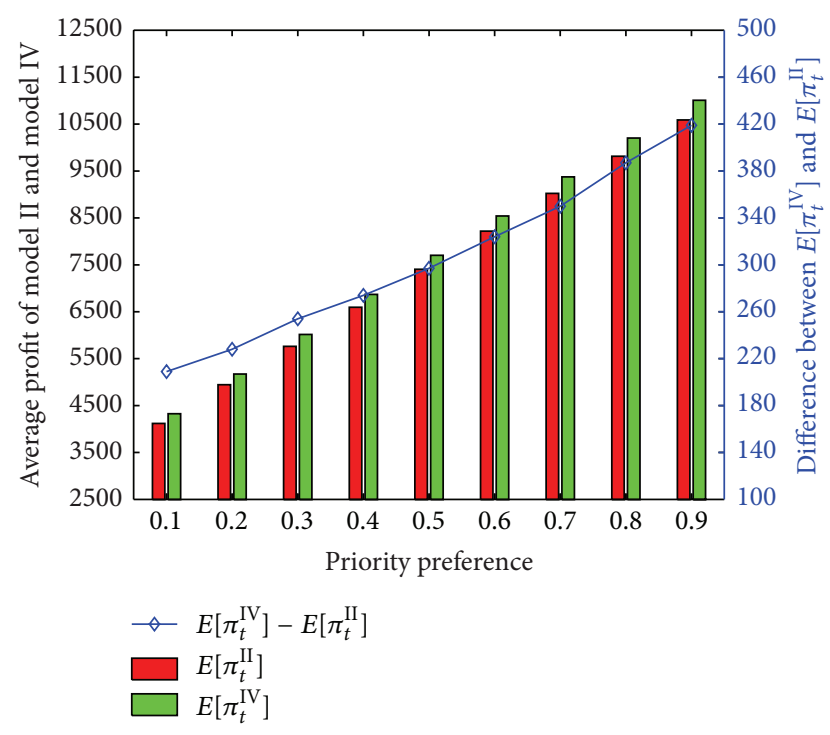

FIGURE 8: Average profits of model II and model IV.

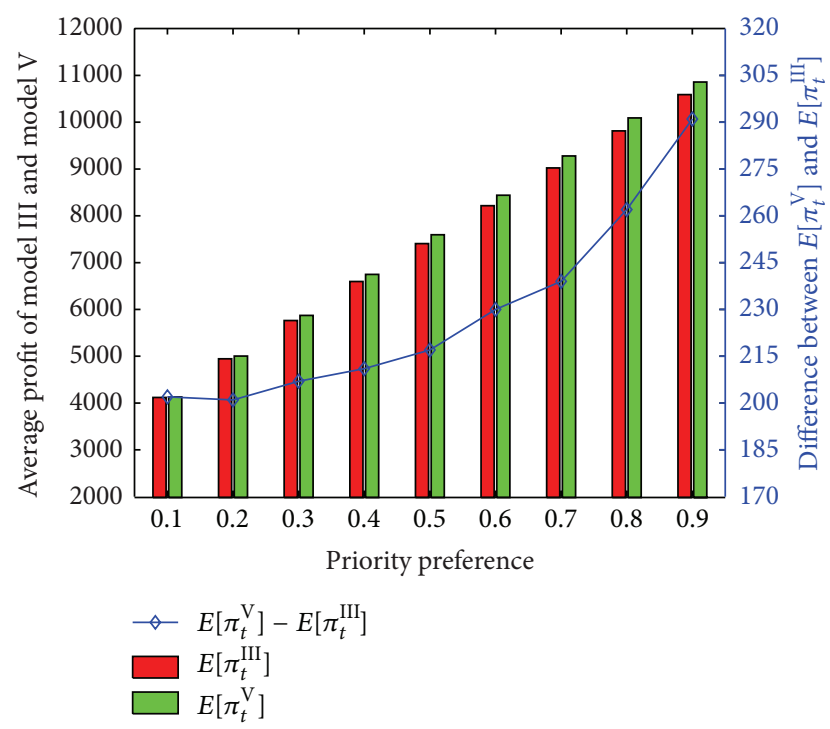

FIGURE 9: Average profits of model III and model V.

an upward trend with the rising of priority preference, because of the e-tailer getting more margins from the hybrid channel than single traditional channel. When the priority preference changes from 0.1 to 0.9 , the average profit of model II rises from $\$ 4118$ to $\$ 10590$, and that of model IV increases from $\$ 4327$ to $\$ 11009$. In addition, the average profit of model IV is always higher than model II; it is the reason why the etailer chooses drop shipping as an e-fulfillment option. Drop shipping brings a channel to make profit for the e-tailer when in-house inventory is stock out. Furthermore, the average profit difference between model IV and model II has an improving trend with the increasing of priority preference. More priority demand satisfied by drop shipping rather than lost sale means that more margins are being obtained by the e-tailer. The comparison between model IV and model I
TABLE 2: Average profits of the e-tailer with $M D C=1.4$.

\begin{tabular}{lccccc}
\hline MDP & $E\left[\pi_{t}^{\mathrm{I}}\right]$ & $E\left[\pi_{t}^{\mathrm{II}}\right]$ & $E\left[\pi_{t}^{\mathrm{III}}\right]$ & $E\left[\pi_{t}^{\mathrm{IV}}\right]$ & $E\left[\pi_{t}^{\mathrm{V}}\right]$ \\
\hline 1.0 & $\$ 1857.5$ & $\$ 748.7$ & $\$ 748.8$ & $\$ 945.9$ & $\$ 945.9$ \\
1.3 & $\$ 2068.2$ & $\$ 1091.1$ & $\$ 1092.6$ & $\$ 1305.7$ & $\$ 1305.7$ \\
1.6 & $\$ 2276.8$ & $\$ 1440.2$ & $\$ 1449.5$ & $\$ 1676.3$ & $\$ 1676.4$ \\
1.9 & $\$ 2487.7$ & $\$ 1793.4$ & $\$ 1816.5$ & $\$ 2044.8$ & $\$ 2045.3$ \\
2.2 & $\$ 2694.1$ & $\$ 2138.2$ & $\$ 2178.8$ & $\$ 2406.6$ & $\$ 2408.5$ \\
2.5 & $\$ 2904.8$ & $\$ 2487.7$ & $\$ 2548.1$ & $\$ 2774.9$ & $\$ 2778.9$ \\
2.8 & $\$ 3115.0$ & $\$ 2832.8$ & $\$ 2917.9$ & $\$ 3137.4$ & $\$ 3146.8$ \\
3.1 & $\$ 3325.0$ & $\$ 3185.6$ & $\$ 3294.3$ & $\$ 3514.4$ & $\$ 3528.3$ \\
3.4 & $\$ 3532.5$ & $\$ 3522.3$ & $\$ 3658.4$ & $\$ 3870.1$ & $\$ 3890.8$ \\
3.7 & $\$ 3743.1$ & $\$ 3880.9$ & $\$ 4030.6$ & $\$ 4232.2$ & $\$ 4256.6$ \\
4.0 & $\$ 3954.2$ & $\$ 4233.2$ & $\$ 4415.6$ & $\$ 4608.1$ & $\$ 4642.2$ \\
\hline
\end{tabular}

presents the advantage of hybrid channel compared to single drop shipping channel, and Figure 9 shows the average profit difference between model V and model III, which both have a similar trend to the above; these three comparisons all confirm the value of the hybrid channel strategy for the etailer.

\section{Optimal Choices of the E-Tailer with Channel Difference Variability}

In this section, the optimal choices of the e-tailer with channel differences variability are analyzed, which include the variability of margin difference of priority and margin difference of channel. For simplicity, MDP and MDC are used to represent them, separately. And experiment results show that the variability of MDP and MDC is very important for the e-tailer to make tactical decision under multiperiod environment.

5.1. Optimal Choices of the E-Tailer with Margin Difference of Priority Variability. Given three different MDC levels, the influences of MDP on the optimal choices of the e-tailer are analyzed. Figure 10 shows the scenario with MDC level is 1.0, which means that the e-tailer obtaining the same units of margin from the same units of demand with the same type in two different channels, and the optimal choice of the etailer is unique; whether MDP level is high or low, the e-tailer always chooses model I, which is the pure-play drop shipping model. When given MDC level becomes 1.4, the e-tailer will adopt model I before point $\mathrm{E}$ and model $\mathrm{V}$ after this point, which can be seen in Figure 11. If MDC level further rises to 1.8 , the optimal choice of the e-tailer becomes model V, where the e-tailer's average profit is the highest one in five models with all levels of MDP.

In addition, the average profit differences between model $\mathrm{V}$ and model IV are relatively small in Figures 10, 11, and 12; Table 2 shows the details of these differences with given MDC level of 1.4, like that between model III and model II.

5.2. Optimal Choices of the E-Tailer with Margin Difference of Channel Variability. Similar to the analysis of MDP in 


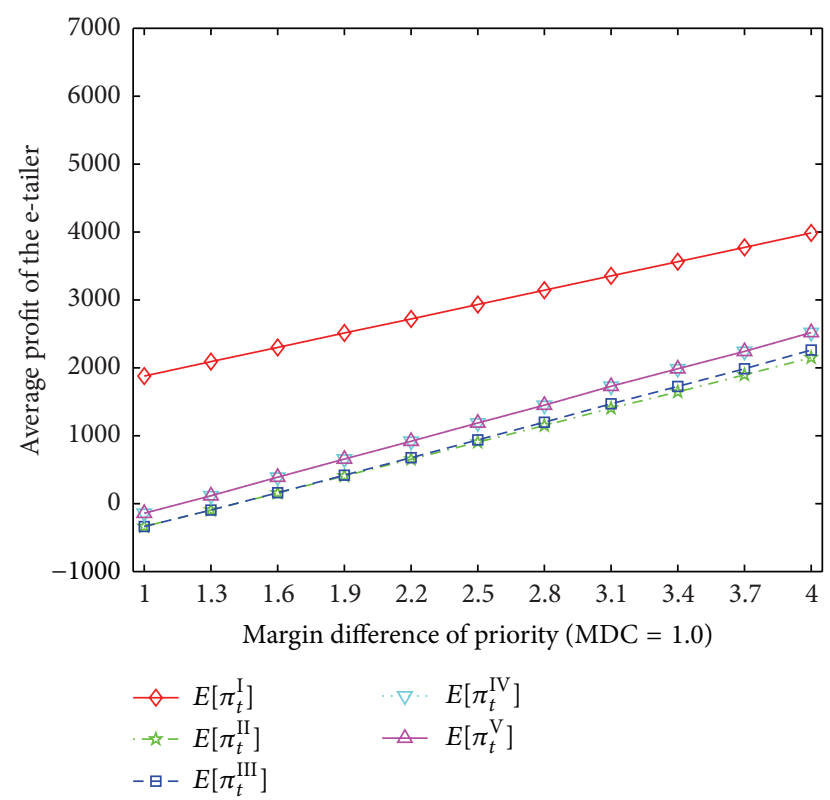

FIGURE 10: Impact of MDP on the e-tailer's average profits with $\mathrm{MDC}=1.0$.

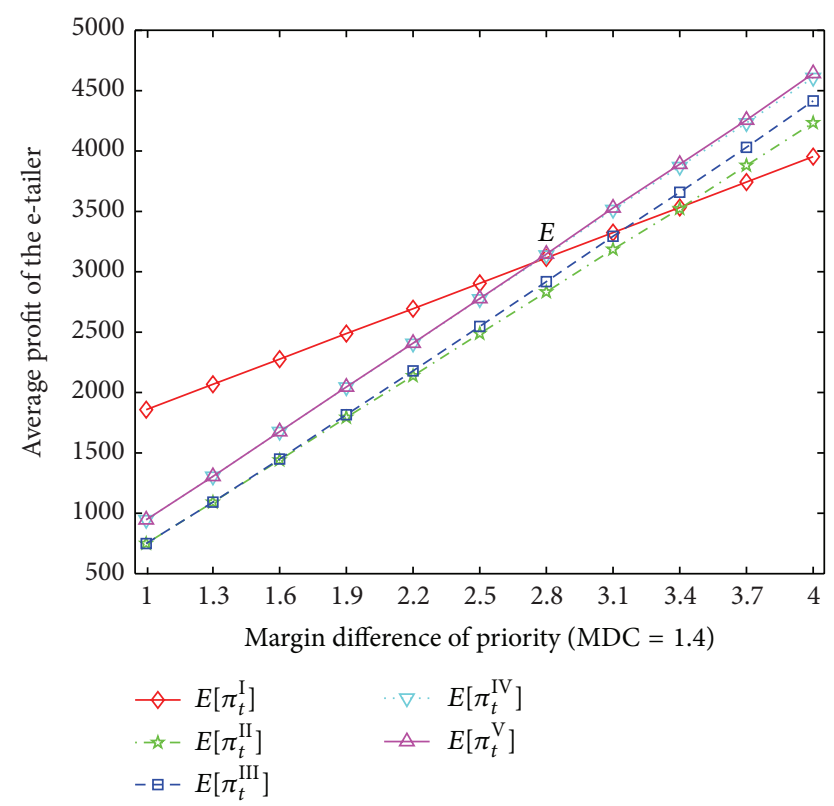

FIGURE 11: Impact of MDP on the e-tailer's average profits with MDC $=1.4$.

Section 5.1, the impact of MDC on the optimal choices of the e-tailer with given three different levels of MDP is evaluated. From Figures 13, 14, and 15, the same order of the e-tailer's optimal choices has been obtained. With the increasing of MDC level under certain given MDP levels, the e-tailer chooses model I before the threshold point (e.g., $F$ in Figure 13) and model V after this point. The difference of the e-tailer's optimal choices with different levels of MDP just represents the different positions of the threshold point. This threshold point forwards itself to the direction to zero point

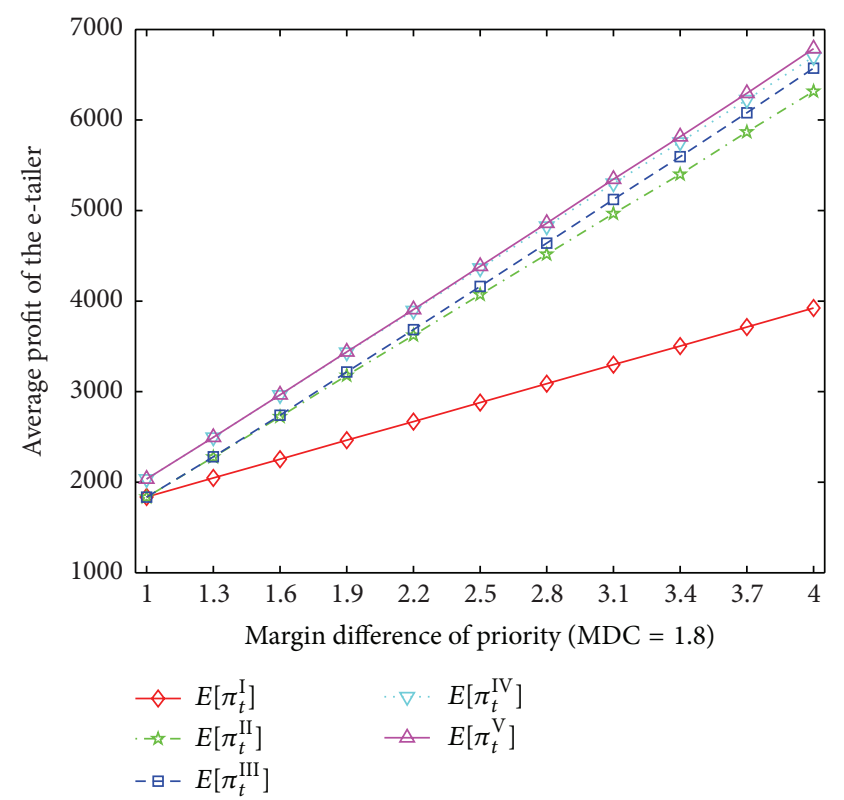

FIGURE 12: Impact of MDP on the e-tailer's average profits with MDC $=1.8$.

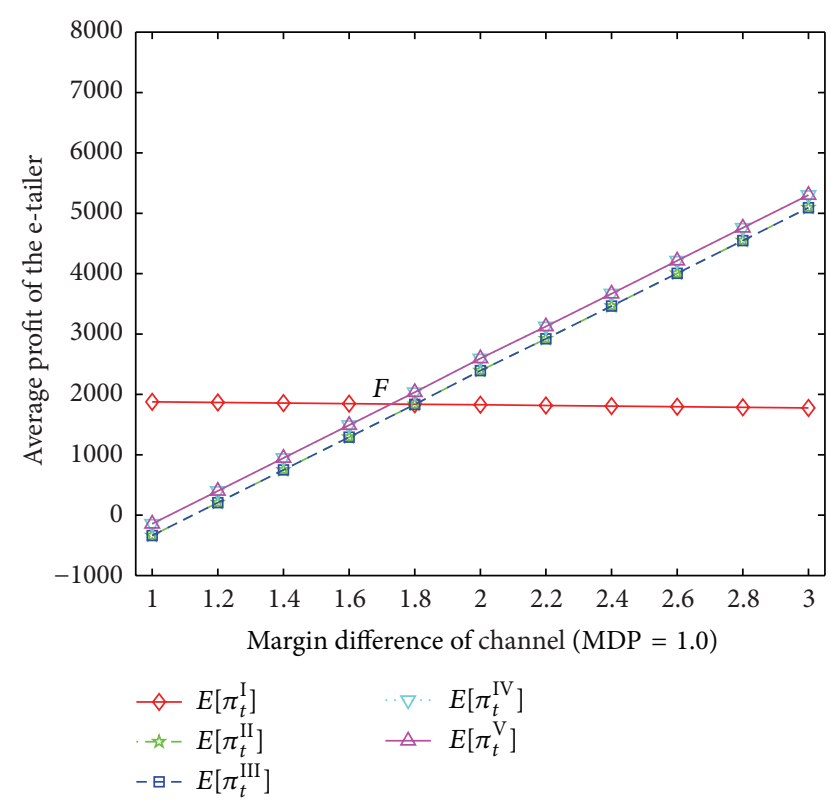

FIGURE 13: Impact of MDC on the e-tailer's average profits with MDP $=1.0$.

with the rising of MDP level and $\mathrm{MDC}_{F}>\mathrm{MDC}_{G}>\mathrm{MDC}_{H}$, where $\mathrm{MDC}_{M}$ is the MDC level at point $M$ in Figures 13, 14 , and $15, M \in\{F, G, H\}$. In other words, it means that the e-tailer's adoption scale of model I becomes smaller when MDP level rises; meanwhile, the choice chance of model V is improved for the e-tailer; this result is consistent with the conclusion in Section 5.1. In addition, the average profit differences between model $\mathrm{V}$ and model IV are also relatively small, and Table 3 shows these differences in detail when 


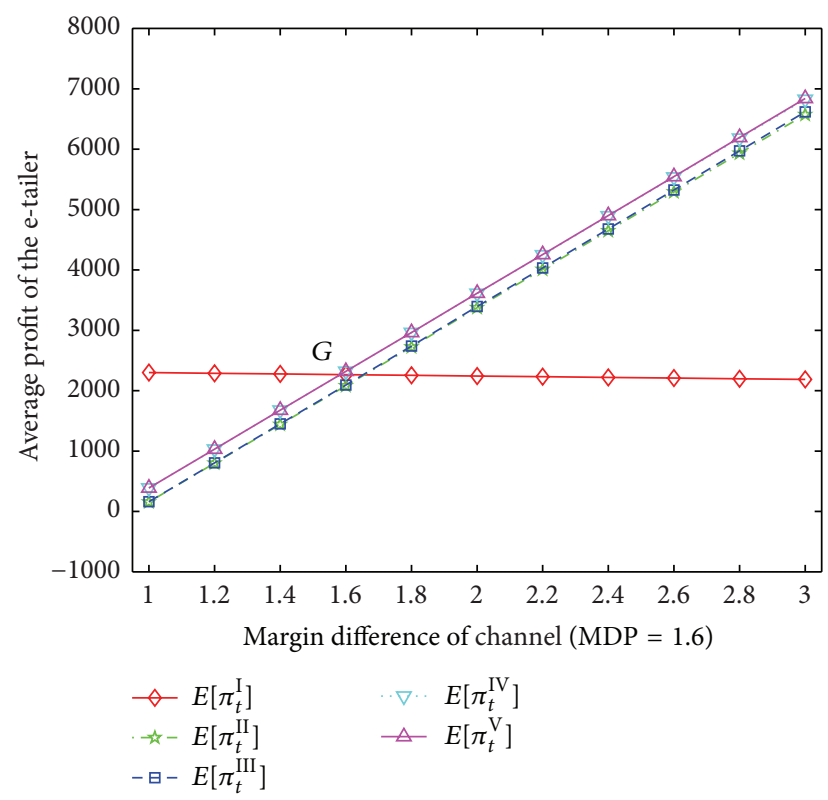

FIGURE 14: Impact of MDC on the e-tailer's average profits with MDP $=1.6$.

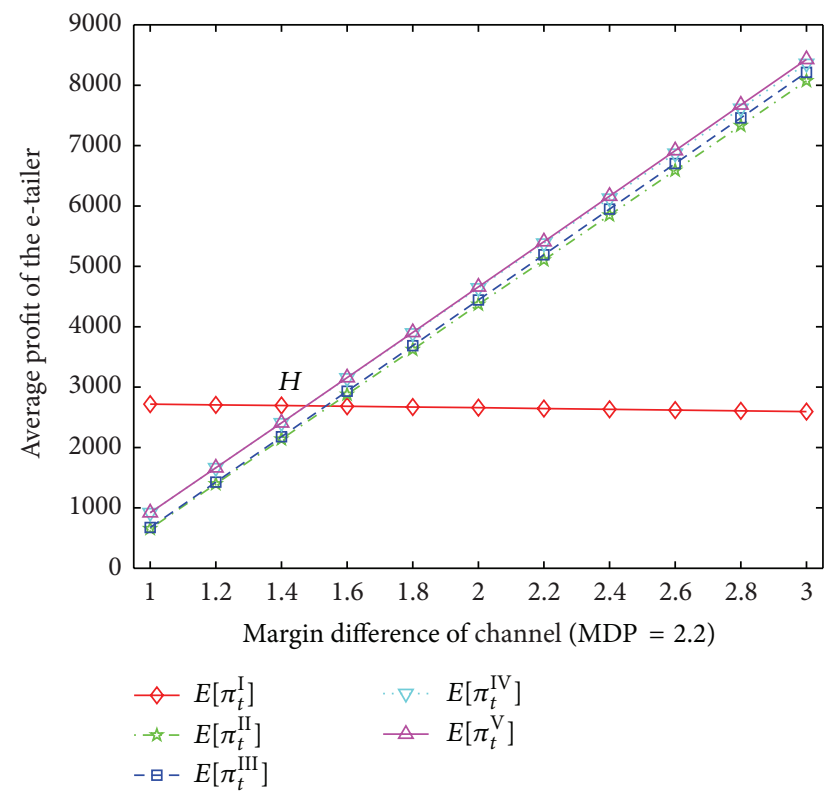

FIGURE 15: Impact of MDC on the e-tailer's average profits with MDP $=2.2$.

MDC level changes from 1.0 to 3.0 with given MDP level as 1.6, like that between model III and model II.

\section{Conclusions}

Based on inventory rationing and hybrid channel strategies, this paper analyzes five mathematical models for the etailer under multiperiod environment with service level constraint, fuzzy demand, and fuzzy lead time through computer simulation. A general framework is designed to illustrate
TABLE 3: Average profits of the e-tailer with MDP $=1.6$.

\begin{tabular}{lccccc}
\hline MDC & $E\left[\pi_{t}^{\mathrm{I}}\right]$ & $E\left[\pi_{t}^{\mathrm{II}}\right]$ & $E\left[\pi_{t}^{\mathrm{III}}\right]$ & $E\left[\pi_{t}^{\mathrm{IV}}\right]$ & $E\left[\pi_{t}^{\mathrm{V}}\right]$ \\
\hline 1.0 & $\$ 2299.4$ & $\$ 156.7$ & $\$ 160.7$ & $\$ 388.7$ & $\$ 388.7$ \\
1.2 & $\$ 2288.1$ & $\$ 798.5$ & $\$ 804.8$ & $\$ 1032.5$ & $\$ 1032.5$ \\
1.4 & $\$ 2276.8$ & $\$ 1440.2$ & $\$ 1449.5$ & $\$ 1676.3$ & $\$ 1676.4$ \\
1.6 & $\$ 2265.5$ & $\$ 2081.9$ & $\$ 2094.7$ & $\$ 2320.2$ & $\$ 2320.5$ \\
1.8 & $\$ 2254.3$ & $\$ 2723.6$ & $\$ 2740.3$ & $\$ 2964.0$ & $\$ 2964.9$ \\
2.0 & $\$ 2241.7$ & $\$ 3375.2$ & $\$ 3394.2$ & $\$ 3613.0$ & $\$ 3614.7$ \\
2.2 & $\$ 2231.7$ & $\$ 4007.1$ & $\$ 4032.5$ & $\$ 4251.6$ & $\$ 4255.3$ \\
2.4 & $\$ 2220.4$ & $\$ 4648.8$ & $\$ 4679.0$ & $\$ 4895.5$ & $\$ 4901.0$ \\
2.6 & $\$ 2209.1$ & $\$ 5291.0$ & $\$ 5326.0$ & $\$ 5539.0$ & $\$ 5548.0$ \\
2.8 & $\$ 2197.9$ & $\$ 5932.0$ & $\$ 5973.0$ & $\$ 6183.0$ & $\$ 6195.0$ \\
3.0 & $\$ 2186.6$ & $\$ 6574.0$ & $\$ 6620.0$ & $\$ 6827.0$ & $\$ 6842.0$ \\
\hline
\end{tabular}

the operational processes of different e-tailer models; the advantages of inventory rationing and hybrid channel strategies are evaluated when the e-tailer aims to maximize average profit with two types of demand, and the optimal choices of the e-tailer are obtained within different mathematical models. The mixture influences of margin differences of priority and channel on the optimal choices for the e-tailer are also considered. The results show that inventory rationing and hybrid channel strategies can bring more margins to the e-tailer, and the additional margins become more with the rising of margin difference of channel. The pure-play drop shipping model and the hybrid channel with inventory rationing model are the optimal choices for the e-tailer. In addition, this research has some extensions; when the cost of running an inventory system becomes higher, or the margins obtained from in-house inventory are decreasing, and so forth, the optimal choices of the e-tailer will become uncertain under these scenarios; these problems should be concerned and studied in the future.

\section{Notations and Parameters}

$D_{t}$ : Total demand, a triangular fuzzy number

$D_{t, i}$ : The class $i_{\text {th }}$ demand, $i \in\{1,2\}$. $D_{t, 1}=\theta \cdot D_{t}$ is the priority demand and $D_{t, 2}=(1-\theta) \cdot D_{t}$ is the common demand. $\theta$ is the proportion of the priority demand in $D_{t}$

$w_{i}$ : Unit margin of using in-house inventory to fulfill class $i_{\text {th }}$ demand, $i \in\{1,2\}$ and $w_{1}>w_{2}$

$v_{i}$ : Unit margin of using drop shipping to fulfill class $i_{\text {th }}$ demand, and $w_{i} \geq v_{i}$, $i \in\{1,2\}, v_{1}>v_{2}$

$L: \quad$ Lead time, a triangular fuzzy number

$c$ : The optimal threshold value

$R$ : Stock reorder point

Q: Order lot size

$P_{t}^{j}$ : Inventory position of in-house inventory at time $t$ in e-tailer model $j, j \in\{$ II, III, IV, V $\}$ 
$X_{t}^{j}$ : On hand stock of in-house inventory at time $t$ in e-tailer model

$j, j \in\{\mathrm{II}, \mathrm{III}, \mathrm{IV}, \mathrm{V}\}$

$\mathrm{O}_{t}^{j}$ : $\quad$ Units on order of in-house inventory at time $t$ in e-tailer model $j, j \in\{$ II, III, IV, V $\}$

$D_{t, i}^{\text {inv } j}:$ Class $i_{\text {th }}$ demand fulfilled by in-house inventory in e-tailer model $j$, $i \in\{1,2\}, j \in\{\mathrm{II}, \mathrm{III}, \mathrm{IV}, \mathrm{V}\}$

$D_{t, i}^{\mathrm{ds}, j}$ : Class $i_{\text {th }}$ demand fulfilled by drop shipping in e-tailer model $j$, $i \in\{1,2\}, j \in\{\mathrm{I}, \mathrm{III}, \mathrm{IV}, \mathrm{V}\}$

$D_{t, i}^{\mathrm{ls}, j}: \quad$ Lost sale of class $i_{\text {th }}$ demand in e-tailer model $j, i \in\{1,2\}, j \in\{\mathrm{I}, \mathrm{II}, \mathrm{III}, \mathrm{IV}, \mathrm{V}\}$

$h$ : Inventory holding cost per unit per time

$k$ : Inventory ordering cost per replenishment

$l_{i}$ : $\quad$ Service level of the supplier's drop shipping for class $i_{\text {th }}$ demand, $i \in\{1,2\}$ and $l_{1} \geq l_{2}$

$\mathrm{pc}_{i}$ : Penalty cost per unit of class $i_{\text {th }}$ demand, $i \in\{1,2\}$ and $\mathrm{pc}_{1} \geq \mathrm{pc}_{2}$

$\pi_{t}^{j}$ : Profit function of the e-tailer in model $j, j \in\{$ I, II, III, IV , V $\}$

$\mathrm{fp}_{t}^{j}$ : $\quad$ Flag of placing an order at time $t$ in e-tailer model $j$, and $\mathrm{fp}_{t}^{j} \in\{0,1\}, j \in\{$ II, III, IV, $\mathrm{V}\}$

$\mathrm{fa}_{t}^{j}$ : Flag of arriving an order at time $t$ in e-tailer model $j$, and $\mathrm{fa}_{t}^{j} \in\{0,1\}, j \in\{\mathrm{II}, \mathrm{III}, \mathrm{IV}, \mathrm{V}\}$.

\section{Conflict of Interests}

The authors declare that there is no conflict of interests regarding the publication of this paper.

\section{Acknowledgments}

This work is supported by the Research Fund for the Doctoral Program of Higher Education of China (no. 20100032110034), the Research Fund of Humanities and Social Sciences of the Ministry of Education of China (no. 12YJAZH052), and Langfang Science and Technology Support Program (no. 2015011065).

\section{References}

[1] Ministry of Commerce of the People's Republic of China, China's E-Commerce, China Commerce and Trade Press, Beijing, China, 2015.

[2] Beijing Times, "Tmail breaks 9 Guiness world record during the Single's Day," December 2014, http://epaper.jinghua.cn/html/ 2015-11/14/node_356.htm.

[3] S. Netessine and N. Rudi, "Supply chain choice on the internet," Management Science, vol. 52, no. 6, pp. 844-864, 2006.

[4] M. J. Kleijn and R. Dekker, "Using break quantities for tactical optimisation in multi-stage distribution systems," in Advances in Distribution Logistics, B. Fleischmann, J. A. E. E. van Nunen,
M. G. Speranza, and P. Stahly, Eds., pp. 305-317, Springer, Berlin, Germany, 1998.

[5] K. C. Frank, R. Q. Zhang, and I. Duenyas, "Optimal policies for inventory systems with priority demand classes," Operations Research, vol. 51, no. 6, pp. 993-1002, 2003.

[6] Y. Wang, S. H. Zhang, and L. Sun, "Anticipated rationing policy for two demand classes under service level constraints," Computers and Industrial Engineering, vol. 65, no. 2, pp. 331340, 2013.

[7] G. R. Bitran and S. V. Mondschein, "An application of yield management to the hotel industry considering multiple day stays," Operations Research, vol. 43, no. 3, pp. 427-443, 1995.

[8] M. K. Geraghty and E. Johnson, "Revenue management saves national car rental," Interfaces, vol. 27, no. 1, pp. 107-127, 1997.

[9] J. Subramanian, S. Stidham Jr., and C. J. Lautenbacher, "Airline yield management with overbooking, cancellations, and noshows," Transportation Science, vol. 33, no. 2, pp. 147-167, 1999.

[10] A. Ayanso, M. Diaby, and S. K. Nair, "Inventory rationing via drop-shipping in internet retailing: a sensitivity analysis," European Journal of Operational Research, vol. 171, no. 1, pp. 135152, 2006.

[11] G. Li, Y.-C. Kang, and G. Xu, "Optimal decision for fashion supply chains with service level constraint and controllable lead time," Mathematical Problems in Engineering, vol. 2015, Article ID 758494, 9 pages, 2015.

[12] M. F. Yang and W.-C. Tseng, "Three-echelon inventory model with permissible delay in payments under controllable lead time and backorder consideration," Mathematical Problems in Engineering, vol. 2014, Article ID 809149, 16 pages, 2014.

[13] I. Moon and S. Kang, "Rationing policies for some inventory systems," Journal of the Operational Research Society, vol. 49, no. 5, pp. 509-518, 1998.

[14] H.-C. Hung, E. P. Chew, L. H. Lee, and S. Liu, "Dynamic inventory rationing for systems with multiple demand classes and general demand processes," International Journal of Production Economics, vol. 139, no. 1, pp. 351-358, 2012.

[15] R. V. Evans, "Sales and restocking policies in a single item inventory system," Management Science, vol. 14, no. 7, pp. 463472, 1968.

[16] A. Y. Ha, "Inventory rationing in a make-to-stock production system with several demand classes and lost sales," Management Science, vol. 43, no. 8, pp. 1093-1103, 1997.

[17] K. P. S. Isotupa and S. K. Samanta, "A continuous review $(\mathrm{s}, \mathrm{Q})$ inventory system with priority customers and arbitrarily distributed lead times," Mathematical and Computer Modelling, vol. 57, no. 5-6, pp. 1259-1269, 2013.

[18] A. F. Veinott Jr., "Optimal policy in a dynamic, single product, non-stationary inventory model with several demand classes," Operations Research, vol. 13, no. 5, pp. 761-778, 1965.

[19] S. Nahmias and W. S. Demmy, "Operating characteristics of an inventory system with rationing," Management Science, vol. 27, no. 11, pp. 1236-1245, 1981.

[20] P. Melchiors, R. Dekker, and M. J. Kleijn, "Inventory rationing in an (s, Q) inventory model with lost sale and two demand classes," Journal of the Operational Research Society, vol. 51, no. 1, pp. 111-122, 2000.

[21] K. T. Möllering and U. W. Thonemann, "An optimal critical level policy for inventory systems with two demand classes," Naval Research Logistics, vol. 55, no. 7, pp. 632-642, 2008.

[22] K. D. Cattani and G. C. Souza, "Inventory rationing and shipment flexibility alternatives for direct market firms," Production and Operations Management, vol. 11, no. 4, pp. 441-457, 2002. 
[23] E. P. Chew, L. H. Lee, and S. D. Liu, "Dynamic rationing and ordering policies for multiple demand classes," OR Spectrum, vol. 35, no. 1, pp. 127-151, 2013.

[24] The state of e-Retailing 2000, E-retailing World, March 2000.

[25] M. Khouja, "The evaluation of drop shipping option for ecommerce retailers," Computers and Industrial Engineering, vol. 41, no. 2, pp. 109-126, 2001.

[26] Y. P. Cheng, B. Li, and Y. N. Li, "Analysis of uncertainty influence on an e-tailer with a threshold policy and alternative e-fulfillment options," WSEAS Transactions on Information Science and Applications, vol. 12, pp. 277-289, 2015.

[27] S. Netessine, T. Randall, and N. Rudi, "Can e-tailers find fulfillment with drop-shipping?” Knowledge @ Wharton, 2002, http://knowledge.wharton.upenn.edu/article/can-e-tailersfind-fulfillment-with-drop-shipping/.

[28] F. Y. Chen, S. H. Hum, and C. H. Sim, "On inventory strategies of online retailers," Journal of Systems Science and Systems Engineering, vol. 14, no. 1, pp. 52-72, 2005.

[29] J. P. Bailey and E. Rabinovich, "Internet book retailing and supply chain management: an analytical study of inventory location speculation and postponement," Transportation Research Part E: Logistics and Transportation Review, vol. 41, no. 3, pp. 159177, 2005.

[30] M. Khouja and A. C. Stylianou, "A (Q, R) inventory model with a drop-shipping option for e-business," Omega, vol. 37, no. 4, pp. 896-908, 2009. 


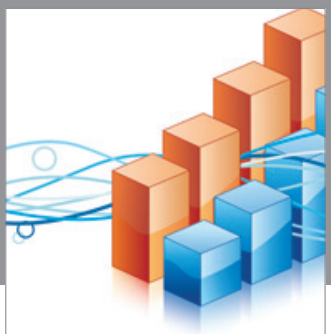

Advances in

Operations Research

vatem alat4

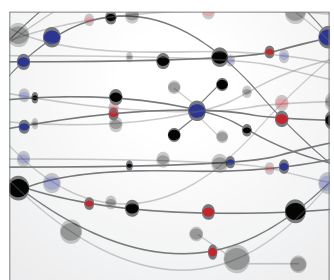

\section{The Scientific} World Journal
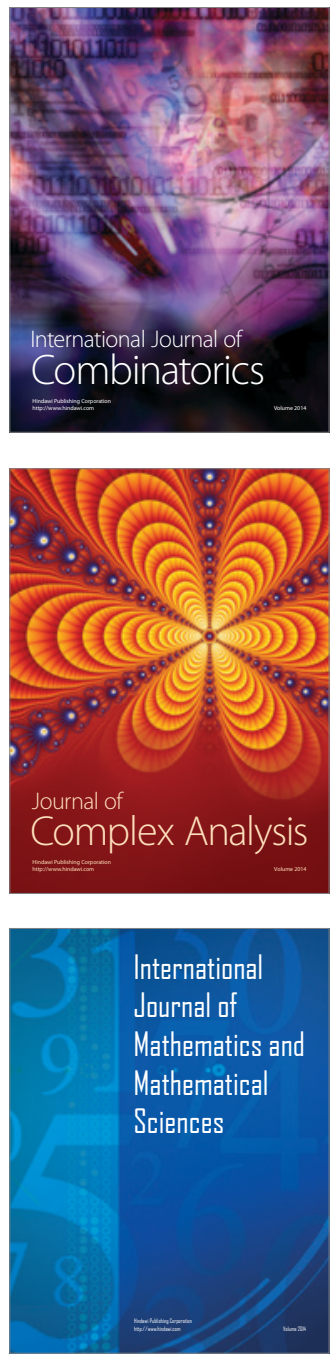
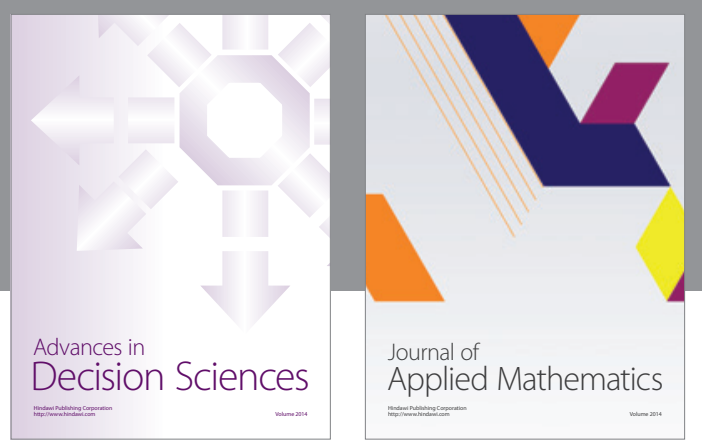

Algebra

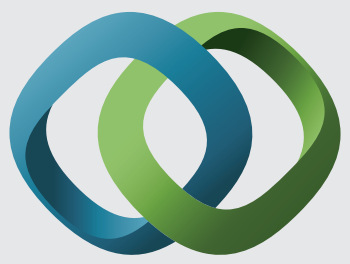

\section{Hindawi}

Submit your manuscripts at

http://www.hindawi.com
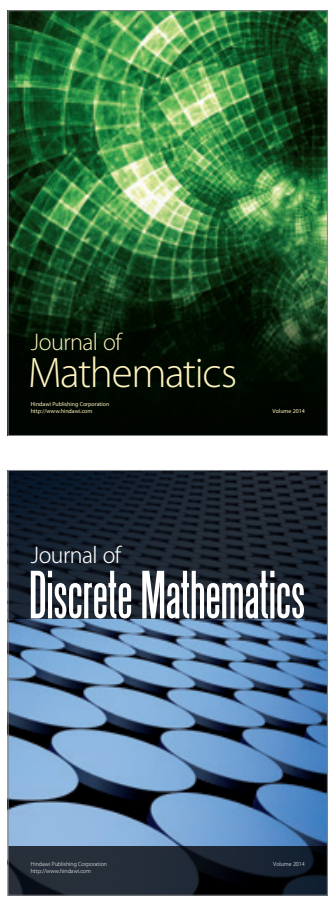

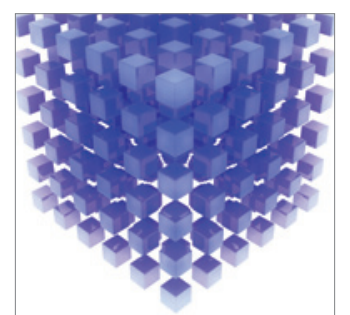

Mathematical Problems in Engineering
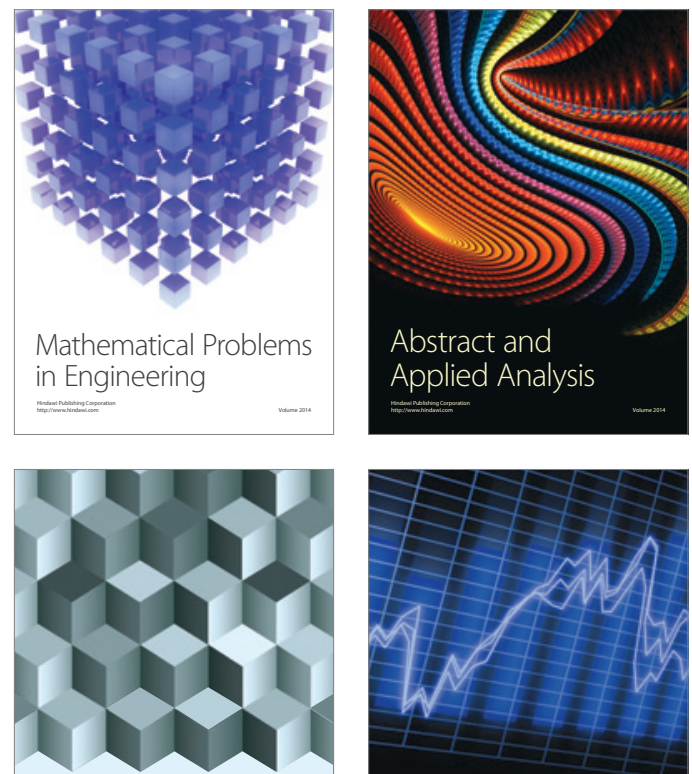

Journal of

Function Spaces

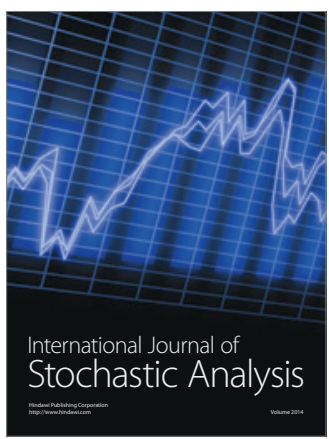

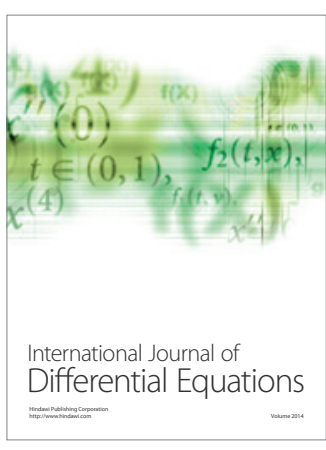
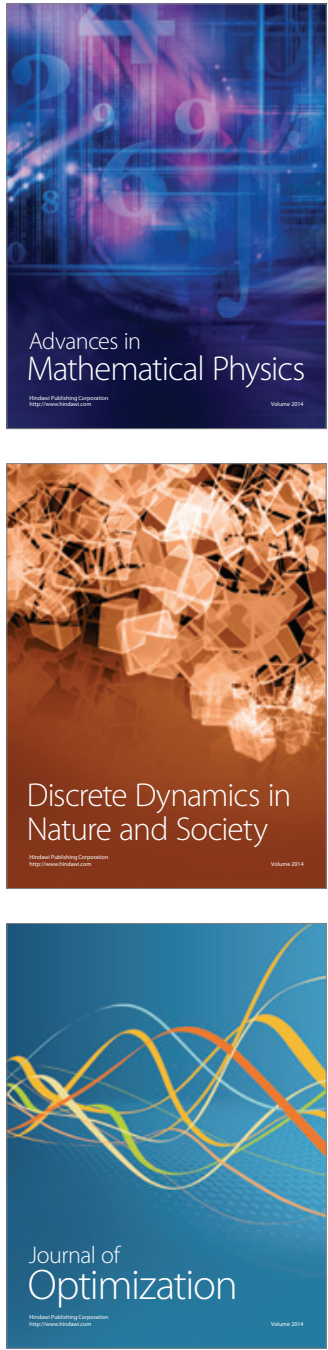